\author{
Chunfa $\mathrm{Wu}^{1}$ \\ Yongming Luo ${ }^{2}$ \\ Tong Gui ${ }^{3}$ \\ Shihong Yan ${ }^{4}$ \\ ${ }^{1}$ Nanjing University of Information \\ Science and Technology, Nanjing, \\ P. R. China \\ ${ }^{2}$ Yantai Institute of Coastal Zone \\ Research, Chinese Academy of \\ Sciences, Yantai, P. R. China \\ ${ }^{3}$ College of Biology and Environmental \\ Engineering, Jiangsu University of \\ Science and Technology, Jiangsu, \\ P. R. China \\ ${ }^{4}$ School of Earth and Environment, \\ Anhui University of Science and \\ Technology, Huainan, P. R. China
}

\section{Research Article \\ Characteristics and Potential Health Hazards of Organochlorine Pesticides in Shallow Groundwater of Two Cities in the Yangtze River Delta}

\begin{abstract}
A total of 52 shallow groundwater samples were collected from two cities, Shengzhou and Shangyu, in the Yangtze River Delta, to characterize the residues of hexachlorocyclohexane $(\mathrm{HCH})$ isomers and dichlorodiphenyltrichloroethane (DDT) isomers/ metabolites present and estimate health risk of drinking groundwater. $\mathrm{HCH}$ and DDT residues occurred in the shallow groundwater of most of Shengzhou and partial area of Shangyu. Concentrations of total HCH ( $\Sigma$ HCHs) and total DDT ( $\Sigma$ DDTs) in the shallow groundwater ranged from below the detection limit (BDL) to $123.2 \mathrm{ng} \mathrm{L}^{-1}$ and BDL to $321.4 \mathrm{ng} \mathrm{L}^{-1}$ for Shengzhou and BDL to $46.40 \mathrm{ng} \mathrm{L}^{-1}$ and BDL to $77.92 \mathrm{ng} \mathrm{L}^{-1}$ for Shangyu. The predominant $\mathrm{HCH}$ and DDT species in the shallow groundwater of Shengzhou were $\delta$-HCH and $o, p^{\prime}$-DDT, and the equivalent species in Shangyu were $\delta$ - $\mathrm{HCH}$ and $p, p^{\prime}$-DDT. The low $\alpha-\mathrm{HCH} / \gamma-\mathrm{HCH}$ ratio, low (dichlorodiphenylethylene (DDE) + dichlorodiphenyldichloroethane)/ $\Sigma$ DDTs ratio and $0, p^{\prime}$-DDE being the dominant DDT metabolite for the majority of samples collected from Shengzhou suggest that there are fresh inputs of lindane and dicofol mixtures in majority area of Shengzhou. The high ratios of $p, p^{\prime}$-DDT/ $\Sigma$ DDTs in half of the groundwater samples collected from Shangyu suggest that there are fresh inputs of DDT in partial area of Shangyu. $\alpha-\mathrm{HCH}, \beta-\mathrm{HCH}$, and $\gamma-\mathrm{HCH}$ in the shallow groundwater in majority area of Shengzhou are posing serious cancer risks to children $\left(>10^{-6}\right)$, and the three $\mathrm{HCH}$ isomers in the shallow groundwater of Shengzhou should be controlled urgently and effectively.
\end{abstract}

Keywords: DDT; Health risk assessment; Hexachlorohexane; Isomers; Metabolites

Received: November 4, 2012; revised: April 24, 2013; accepted: June 4, 2013

DOI: 10.1002/clen.201200602

\section{Introduction}

Organochlorine pesticides (OCPs) have been widely used in pest and disease control because of their low cost and broad spectrum toxicity and are now of great concern worldwide owing to their chronic toxicity, persistence and bioaccumulation. Previous studies showed that exposure to OCPs can cause disruption of endocrine system [1-3], and accumulation of OCPs has been related to increased risk of various types of human cancer [4-6] and genotoxic effects [7, 8]. Hexachlorocyclohexane $(\mathrm{HCH})$ and dichlorodiphenyltrichloroethane (DDT) are two representative OCPs that have been used extensively in China, mainly in agriculture [9]. China is a major agricultural country and a large producer and user of OCPs. The cumulative consumption of technical $\mathrm{HCH}$ and technical DDT in the mainland had amounted to $4.46[10]$ and 0.27 million tons [11], respectively, on

Correspondence: Dr. Chunfa Wu, Nanjing University of Information Science and Technology, 219 Ningliu Rd, Nanjing 210044, P. R. China E-mail: wchf1680@sina.com

Abbreviations: BDL, below the detection limit; DDD, dichlorodiphenyldichloroethane; DDE, dichlorodiphenylethylene; DDT, dichlorodiphenyltrichloroethane; $\sum$ DDTs, sum of DDT, DDE, DDD; ED, exposure duration; HCH, hexachlorocyclohexane; $\sum \mathrm{HCHs,} \mathrm{sum} \mathrm{of} \mathrm{HCHs;} \mathrm{HQ}$ hazard quotient; IR, water ingestion rate; OCP, organochlorine pesticide; $\mathbf{R}_{\mathbf{f}} \mathbf{D}$, reference dose of the contaminant via oral exposure the mainland before they have been banned for agricultural use in the 1980s. Despite the ban on technical DDT and technical HCH in 1983, dicofol (highly contaminated with DDT compounds) and lindane (almost pure $\gamma-\mathrm{HCH}$ ) have continued to be widely used in agricultural practice in China in recent decades and have become important sources of DDT and HCH pollution in China $[12,13]$.

Because of their environmental persistence and widespread use, residues of $\mathrm{HCH}$ isomers and DDT isomers/metabolites have been detected in almost all environmental compartments including soils $[14,15]$, water bodies $[16,17]$ and the human food chain $[18$, 19]. Concentrations of DDT and $\mathrm{HCH}$ in the environment have decreased in China by banning or restricting their use [20, 21]; however, relatively high residual levels of OCPs have recently been detected in some parts of China [12, 22-24].

There is a substantial body of information about OCP residues in Chinese surface waters and soils/sediments [12, 15, 25-27]. However, there is little information on groundwater contamination, including regions where shallow groundwater is an important source of drinking water. The Yangtze River Delta is an important region for food production with rapid intensification of agriculture where large amounts of OCPs have been used historically to increase agricultural production [11, 28]. It is also a region with water shortages and poor surface water quality despite the use of shallow groundwater as an important source of drinking water. The objectives of the present 
study were: (i) to determine the levels of $\mathrm{HCH}$ isomers and DDT isomers/metabolites in the shallow groundwater of two cities with rapid industrialization and intensification of agriculture; (ii) to identify their possible sources based on the ratios of isomers/ metabolites, and (iii) to estimate human health risk caused by the two OCPs through consumption of the shallow groundwater.

\section{Materials and methods}

\subsection{Description of study area}

The study area covers two coterminous cities, Shengzhou and Shangyu, located on the Ningshao Plain in the northeast of the Yangtze River Delta, China. Both are known for their high inputs of pesticides and chemical fertilizers. The area $\left(29^{\circ} 37.5^{\prime}-30^{\circ} 35.2^{\prime} \mathrm{N}\right.$, $120^{\circ} 19.7^{\prime}-120^{\circ} 59.6^{\prime} \mathrm{E}$ ) is about $3218 \mathrm{~km}^{2}$ and is situated in the northern subtropical monsoon climatic zone with a temperate and humid climate throughout the year and four distinct seasons. The average annual temperature is $16.4^{\circ} \mathrm{C}$ and the mean annual precipitation is approximately $1400 \mathrm{~mm}$, with most precipitation occurring from June through September.

The terrain of Shengzhou exhibits low elevation in the center and high elevation in other areas, and the topography of Shangyu comprises low elevation in the north and high elevation in the south (Fig. 1). The study area covers two physiognomical types, plain and hill. The shallow groundwater type of the plain in the study area is loose rock pore water with corresponding loose rock pore water

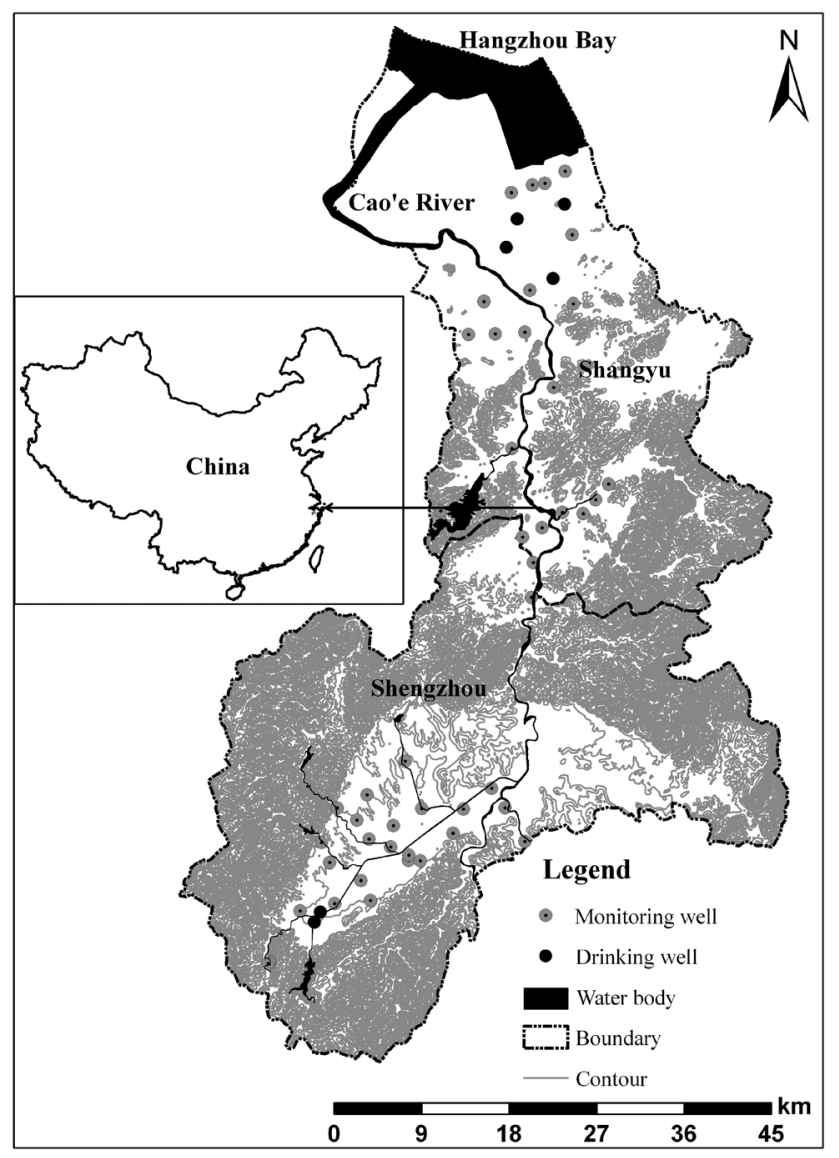

Figure 1. The location of study area and distribution of sampling sites. aquifer. According to hydrogeological data, the thickness of the porous unconfined aquifer is approximately $2-5 \mathrm{~m}$, and the static water table of the shallow groundwater is approximately $0.5-1.5 \mathrm{~m}$ below the ground surface, being deeper in the middle of the study area and shallower in the north and south of the study area [29]. The water table fluctuates both with the seasons and years because it is affected by climatic variation and precipitation with the extent of fluctuation reaching $1 \mathrm{~m}$. Shallow groundwater is an important source of drinking water in the study area because of the poor water quality of the surface waters.

\subsection{Groundwater sampling}

A total of 52 shallow groundwater samples were collected from monitoring wells and drinking wells from November to December 2010 with consideration of uniform distribution, potential pollution sources and convenience of monitoring (the locations are shown in Fig. 1). 30 of the 52 samples were collected from Shengzhou and the remaining 22 from Shangyu. Most of the wells had depths ranging from 3 to $5 \mathrm{~m}$ and the remainder ranged from 5 to $8 \mathrm{~m}$. The groundwater levels during sampling were $0.5-1.2 \mathrm{~m}$ below the ground surface. Groundwater samples were collected following this sequence: (i) pump the tube-well for several minutes; (ii) wash out a clean brown glass bottle with the groundwater; (iii) collect groundwater from $5 \mathrm{~cm}$ below the groundwater table using a polyvinyl chloride Baylor tube and filter the water through a $0.45 \mu \mathrm{m}$ glass-fiber filter (Whatman, Clifton, NJ, USA) to remove sand and debris during field sampling; (iv) fill a $1 \mathrm{~L}$ brown glass bottle with filtered groundwater and acidify with ultra-pure sulfuric acid to $\mathrm{pH}<2$ to inhibit biological activity; (v) seal the bottle using a polytetrafluoroethylene membrane and store the sample in the dark at temperature between 0 and $4{ }^{\circ} \mathrm{C}$ prior to extraction within two days. A filtered groundwater sample was collected from each well, and a field duplicate sample was collected for every 5-8 wells to estimate sampling and laboratory analysis precision.

\subsection{Sample extraction and OCP analysis}

Two hundred fifty milliliters filtered groundwater of each groundwater sample were used to sample extraction, and the "dissolved OCPs" were obtained by liquid-liquid extraction using $25 \mathrm{~mL}$ redistilled cyclohexane. The extract was continuously purified with 3-5 mL concentrated sulfuric acid until the layer of sulfuric acid was colorless. The purified solutions were dried with a rotary evaporator after the water was removed from the purified solutions using anhydrous sodium sulfate and dissolved in $2 \mathrm{~mL}$ $n$-hexane.

All reagents used ( $n$-hexane and cyclohexane) were high performance LC grade purchased from Tedia, Fairfield, $\mathrm{OH}$. The anhydrous sodium sulfate (analytical grade, Shanghai Chemical Reagents) was baked at $450^{\circ} \mathrm{C}$ for $4 \mathrm{~h}$. A standard mixture of $\alpha-\mathrm{HCH}, \beta-\mathrm{HCH}, \gamma-\mathrm{HCH}$, $\delta$-HCH, $\quad 0, p^{\prime}$-DDT, $p, p^{\prime}$-dichlorodiphenyldichloroethane (DDD), $p, p^{\prime}$ dichlorodiphenylethylene (DDE), and $p, p^{\prime}$-DDT was purchased from Dr. Ehrenstorfer (Augsburg, Germany). The purified extracts were analyzed by GC (Varian 3800, Salt Lake City, UT) equipped with a ${ }^{63} \mathrm{Ni}$ electron capture detector (under splitless mode, using a DB-5MS (Agilent) column $30 \mathrm{~m} \times 0.25 \mathrm{~mm}$ id and $0.25 \mu \mathrm{m}$ film thickness. Ultra-high purity $\mathrm{N}_{2}(>99.9999 \%)$ was used as the carrier gas. The oven temperature program was as follows: injector and detector 
temperatures were 240 and $280^{\circ} \mathrm{C}$, respectively, initial run temperature was set at $80^{\circ} \mathrm{C}$, ramped at $100^{\circ} \mathrm{C} \mathrm{min}^{-1}$ to $240^{\circ} \mathrm{C}$, then ramped at $5^{\circ} \mathrm{C} \mathrm{min}^{-1}$ to $270^{\circ} \mathrm{C}$ and held for $0.5 \mathrm{~min}$.

\subsection{Analytical quality controls and quality assurance}

Quantification of the two OCPs groups was determined from the external standard comparing peak area. The correlation coefficients $(r)$ of calibration curves of HCHs and DDTs were all $>0.997$. For every set of ten samples, a procedural blank and spike sample consisting of all reagents was run to check for interference and cross contamination. The method detection limits (MDL) for the two OCPs groups were determined by 3:1 signal to noise value $(\mathrm{S} / \mathrm{N})$, and ranged from 0.24 to $3.04 \mathrm{ng} \mathrm{L}^{-1}$, respectively (Tab. 1). The groundwater was spiked with mixed standards with $2 \mathrm{~mL}$ of $2 \mu \mathrm{g} \mathrm{L}{ }^{-1}$ diluted mixed standard of two OCPs groups before extraction for assessment of recovery rates and seven replicates were measured for isomers/metabolites of each OCP. The spiked recoveries of the two OCPs groups were in the range of $90.0-114 \%$ and the relative standard deviations were in the range of $0.1-4.8 \%$.

\subsection{Health risk assessment model}

Health risk assessment is the process to estimate the nature and probability of adverse health effects in humans who may be exposed to chemicals in contaminated environmental media, now or in the future. Individuals can be exposed to OCPs through several pathways, but oral exposure route is considered to be the most important one $[30,31]$. In this study, a health risk assessment model derived from US EPA (www.epa.gov/iris) [32] is applied to estimate the carcinogenic and non-carcinogenic risks for adults and children consuming the shallow groundwater as their drinking water source. The chronic daily intake (CDI) is used to estimate human exposure to contaminants [33], and is calculated using the following equation:

$\mathrm{CDI}=\frac{C \times \mathrm{IR} \times \mathrm{EF} \times \mathrm{ED}}{\mathrm{BW} \times \mathrm{AT}}$

where $C=$ chemical concentration in water $\left(\mathrm{mgL}^{-1}\right)$; $\mathrm{IR}=$ water ingestion rate $\left(\mathrm{Lday}^{-1}\right)$ (for children: $I R=1$; for adults: $I R=2$ ); $\mathrm{EF}=$ the exposure frequency (350 days year $\left.^{-1}\right) ; \mathrm{ED}=$ exposure duration (year) (for children: $\mathrm{ED}=6$; for adults: $\mathrm{ED}=70$ ); $\mathrm{BW}=$ body weight (kg) (for children: BW $=14$; for adults: $\mathrm{BW}=60$ ); $\mathrm{AT}=$ average lifespan (days) (for children: $\mathrm{AT}=2190$; for adults: $\mathrm{AT}=25550$ ).

Table 1. Recovery and MDLs for the analysis of organocholorine pesticides by GC equipped with a ${ }^{63} \mathrm{Ni}$ electron capture detector

\begin{tabular}{lcccc}
\hline OCP & $\begin{array}{c}\text { Correlation } \\
\text { coefficient (r) }\end{array}$ & $\begin{array}{c}\text { Recovery } \\
\%\end{array}$ & $\begin{array}{c}\text { RSD } \\
\%\end{array}$ & $\begin{array}{c}\text { MDL } \\
\left(\mathrm{ng} \mathrm{L}^{-1}\right)\end{array}$ \\
\hline$\alpha-\mathrm{HCH}$ & 0.9997 & 90 & 2.7 & 0.24 \\
$\beta-\mathrm{HCH}$ & 0.9989 & 98 & 1.4 & 0.96 \\
$\gamma-\mathrm{HCH}$ & 0.9998 & 98 & 3.2 & 0.32 \\
$\delta$-HCH & 0.9977 & 102 & 0.1 & 0.40 \\
$p, p^{\prime}$-DDE & 0.9998 & 102 & 3.6 & 1.12 \\
$p, p^{\prime}$-DDD & 0.9998 & 102 & 4.8 & 2.16 \\
$o, p^{\prime}$-DDT & 0.9992 & 114 & 0.9 & 2.48 \\
$p, p^{\prime}$-DDT & 0.9997 & 106 & 2.5 & 3.04 \\
\hline
\end{tabular}

RSD, relative standard deviation; MDL, method detection limit.
Table 2. Toxicological parameters of OCPs

\begin{tabular}{|c|c|c|}
\hline Parameter & {$\left[\left(\mathrm{mg} \mathrm{kg}^{-1} \text { per day }\right)^{-1}\right]$} & $\begin{array}{c}\mathrm{R}_{\mathrm{f}} \mathrm{D} \\
\left(\mathrm{mg} \mathrm{kg}^{-1} \text { per day) }\right.\end{array}$ \\
\hline$\alpha-\mathrm{HCH}$ & 6.3 & $5.0 \mathrm{E}-4$ \\
\hline$\beta-\mathrm{HCH}$ & 1.8 & $2.0 \mathrm{E}-4$ \\
\hline$\gamma-\mathrm{HCH}$ & 1.3 & $3.0 \mathrm{E}-4$ \\
\hline$\delta-\mathrm{HCH}$ & - & - \\
\hline$p, p^{\prime}-\mathrm{DDE}$ & 0.34 & - \\
\hline$p, p^{\prime}-\mathrm{DDD}$ & 0.24 & $2.0 \mathrm{E}-3$ \\
\hline$o, p^{\prime}$-DDT & - & - \\
\hline$p, p^{\prime}-\mathrm{DDT}$ & 0.34 & $5.0 \mathrm{E}-4$ \\
\hline
\end{tabular}

-, no given parameter value; SF, slope factor.

From the US EPA exposure factors handbook [34], carcinogenic risk $(R)$ is calculated as follows:

$\mathrm{R}=\mathrm{CDI} \times \mathrm{SF}$

where $\mathrm{CDI}$ is the chronic daily intake from the oral exposure route ( $\mathrm{mg} \mathrm{kg}^{-1}$ per day), SF is the slope factor of the contaminant via oral exposure route $\left(\mathrm{mg} \mathrm{kg}^{-1}\right.$ per day) ${ }^{-1}$.

To estimate non-carcinogenic risk, hazard quotient (HQ) is calculated using the following equation:

$\mathrm{HQ}=\frac{\mathrm{CDI}}{\mathrm{R}_{\mathrm{f}} \mathrm{D}}$

where $\mathrm{R}_{\mathrm{f}} \mathrm{D}$ ( $\mathrm{mg} \mathrm{kg}^{-1}$ per day) is the reference dose of the contaminant via oral exposure route. The values of slope factor and reference dose (Tab. 2) for OCPs are obtained from the US EPA Integrated Risk Information System [35].

\section{Results and discussion}

\subsection{Concentrations of HCHs and DDTs in the shallow groundwater of two regions}

A summary description of detection frequency (equivalent to the ratio of the number of samples that the pollutant could be detected to the number of analysis samples), range, mean and median concentration for $\mathrm{HCH}$ and DDT in the two regions is presented in Tab. 3. It was found that all four $\mathrm{HCH}$ isomers $(\alpha-\mathrm{HCH}, \beta-\mathrm{HCH}$, $\gamma-\mathrm{HCH}$, and $\delta-\mathrm{HCH})$ in the shallow groundwater of Shengzhou had a high detection frequency $(70.0-90.0 \%)$ but $\delta-\mathrm{HCH}$ in the shallow groundwater of Shangyu had a low detection frequency $(9.09 \%)$ and the concentrations of $\alpha-\mathrm{HCH}, \beta-\mathrm{HCH}$, and $\gamma-\mathrm{HCH}$ in all groundwater samples collected from Shangyu were below their detection limits. The concentrations of all four $\mathrm{HCH}$ isomers in the shallow groundwater of Shengzhou had a wide range for $\alpha-\mathrm{HCH}$, below detection limit (BDL): $18.48 \mathrm{ng} \mathrm{L}^{-1}$ with a mean of $7.67 \mathrm{ng} \mathrm{L}^{-1}$; $\beta-\mathrm{HCH}, \mathrm{BDL}: 61.12 \mathrm{ngL}^{-1}$ with a mean of $11.26 \mathrm{ngL}^{-1} ; \gamma-\mathrm{HCH}$, BDL: $34.32 \mathrm{ng} \mathrm{L}^{-1}$ with a mean of $12.98 \mathrm{ngL}^{-1}$; and $\delta-\mathrm{HCH}$, BDL: $79.12 \mathrm{ng} \mathrm{L}^{-1}$ with a mean of $26.25 \mathrm{ng} \mathrm{L}^{-1}$, respectively. $\delta-\mathrm{HCH}$ dominated the $\mathrm{HCH}$ isomers in the shallow groundwater of Shengzhou.

All four DDT isomers/metabolites ( $p, p^{\prime}$-DDD, $p, p^{\prime}$-DDE, $o, p$-DDT, and $p, p^{\prime}$-DDT) in the shallow groundwater of Shengzhou also had a high detection frequency (73.0-90.0\%), whereas the two DDT isomers $\left(o, p\right.$-DDT and $p, p^{\prime}$-DDT) in the shallow groundwater of Shangyu had 
Table 3. Summary statistics for the concentrations of $\mathrm{HCH}$ isomers and DDT isomers/metabolites $\left(\mathrm{ng} \mathrm{L}^{-1}\right)$ in the shallow groundwater of the two regions

\begin{tabular}{|c|c|c|c|c|c|}
\hline City & Isomer/metabolite & Range & Mean & Median & $\mathrm{DF}(\%)$ \\
\hline \multirow[t]{10}{*}{ Shengzhou $(n=30)$} & $\alpha-\mathrm{HCH}$ & BDL-18.48 & 7.67 & 7.80 & 90.0 \\
\hline & $\beta-\mathrm{HCH}$ & BDL-61.12 & 11.26 & 6.44 & 70.0 \\
\hline & $\gamma-\mathrm{HCH}$ & BDL-34.32 & 12.98 & 11.88 & 86.7 \\
\hline & $\delta$-HCH & BDL-79.12 & 26.25 & 24.08 & 86.7 \\
\hline & $\Sigma$ LCHs & BDL-123.2 & 58.15 & 53.52 & 90.0 \\
\hline & $p, p^{\prime}-\mathrm{DDE}$ & BDL-40.32 & 17.52 & 20.36 & 86.7 \\
\hline & $p, p^{\prime}-\mathrm{DDD}$ & BDL-38.08 & 12.25 & 8.32 & 73.3 \\
\hline & $0, p^{\prime}$-DDT & BDL-240.6 & 64.55 & 55.12 & 83.3 \\
\hline & $p, p^{\prime}$-DDT & BDL-48.16 & 22.96 & 23.24 & 90.0 \\
\hline & ¿DDTs & BDL-321.4 & 117.3 & 120.3 & 96.7 \\
\hline \multirow[t]{10}{*}{ Shangyu $(n=22)$} & $\alpha-\mathrm{HCH}$ & $\mathrm{BDL}$ & - & - & 0 \\
\hline & $\beta-\mathrm{HCH}$ & BDL & - & - & 0 \\
\hline & $\gamma-\mathrm{HCH}$ & BDL & - & - & 0 \\
\hline & $\delta$-HCH & BDL-46.40 & 2.92 & - & 9.09 \\
\hline & $\Sigma \mathrm{HCHs}$ & BDL-46.40 & 2.92 & - & 9.09 \\
\hline & $p, p^{\prime}-\mathrm{DDE}$ & BDL-12.96 & 1.32 & - & 9.09 \\
\hline & $p, p^{\prime}-\mathrm{DDD}$ & BDL & - & - & 0 \\
\hline & $0, p^{\prime}$-DDT & BDL-39.36 & 5.97 & 2.92 & 59.1 \\
\hline & $p, p^{\prime}$-DDT & BDL-38.56 & 9.51 & 6.78 & 54.5 \\
\hline & EDDTs & BDL-77.92 & 16.80 & 11.72 & 86.4 \\
\hline
\end{tabular}

- , no data.

a moderate detection frequency (54.5-59.1\%) and the concentrations of the two DDT metabolites ( $p, p^{\prime}$-DDD and $p, p^{\prime}$-DDE) in the majority of groundwater samples were below their detection limits. The concentrations of all four DDT isomers/metabolites in the shallow groundwater of Shengzhou had a wide range for $p, p^{\prime}$-DDE, BDL: $40.32 \mathrm{ng} \mathrm{L}^{-1}$ with a mean of $17.52 \mathrm{ng} \mathrm{L}^{-1} ; p, p^{\prime}$-DDD, BDL: $38.08 \mathrm{ng} \mathrm{L}^{-1}$ with a mean of $12.25 \mathrm{ng} \mathrm{L}^{-1}$; 0 ,p-DDT, BDL: $240.6 \mathrm{ng} \mathrm{L}^{-1}$ with a mean of $64.55 \mathrm{ng} \mathrm{L}^{-1}$; and $p, p^{\prime}$-DDT, and BDL: $48.16 \mathrm{ng} \mathrm{L}^{-1}$ with a mean of $22.96 \mathrm{ng} \mathrm{L}^{-1}$, respectively. The concentrations of the two DDT isomers in the shallow groundwater of Shangyu also had a wide range for $o, p$-DDT, BDL: $39.36 \mathrm{ng} \mathrm{L}^{-1}$ with a mean of $5.68 \mathrm{ng} \mathrm{L}^{-1}$; and $p, p^{\prime}$-DDT, BDL: $38.56 \mathrm{ng} \mathrm{L}^{-1}$ with a mean of $6.74 \mathrm{ng} \mathrm{L}^{-1}$, respectively. $0, p^{\prime}$-DDT dominated the DDT isomers/metabolites in the shallow groundwater of Shengzhou. However, $p, p^{\prime}$-DDT dominated the DDT isomers/ metabolites in the shallow groundwater of Shangyu.

Both mean and median concentrations and detection frequencies of HCH and DDT isomers/metabolites in the shallow groundwater of Shengzhou were higher than those of Shangyu (Tab. 3), indicating that the shallow groundwater of Shengzhou was more polluted with HCHs and DDTs than that of Shangyu. Differences in application rates and environmental conditions between the two regions may explain this finding. The $\Sigma \mathrm{HCHs}$ concentration (equivalent to the sum of $\alpha-+\beta-+\gamma-+\delta-\mathrm{HCH})$ in the shallow groundwater had a wide range at Shengzhou, BDL: $123.2 \mathrm{ngL}^{-1}$ with a mean of $58.15 \mathrm{ngL}^{-1}$; Shangyu, BDL: $46.40 \mathrm{ng} \mathrm{L}^{-1}$ with a mean of $2.92 \mathrm{ng} \mathrm{L}^{-1}$, respectively; and the $\Sigma$ DDTs (equivalent to the sum of $p, p^{\prime}-\mathrm{DDD}+p, p^{\prime}-\mathrm{DDE}+$ $o, p^{\prime}$-DDT $+p, p^{\prime}$-DDT) in the shallow groundwater also had a wide range at Shengzhou, BDL: 321.4 with a mean of $117.3 \mathrm{ng} \mathrm{L}^{-1}$; Shangyu, BDL: $77.92 \mathrm{ng} \mathrm{L}^{-1}$ with a mean of $16.80 \mathrm{ng} \mathrm{L}^{-1}$, respectively. This indicates that the ban or restriction in use has not completely eliminated $\mathrm{HCH}$ and DDT residues from the shallow groundwater of the study area.

The $\mathrm{\Sigma HCH}$ and $\mathrm{LDDT}$ concentrations in the shallow groundwater of the study area had similar distribution trends with the high concentrations in the southwest area (Shengzhou plain) and low concentrations in the northern area (see Fig. 2), suggesting that HCHs and DDTs had similar pollution source. The shallow groundwater aquifer in Shengzhou is comprised of sandy loam or sandy soil, and the shallow groundwater aquifer in Shangyu is comprised of medium loam or heavy loam. So, the permeability of shallow groundwater aquifer in Shengzhou was relatively higher than that in Shangyu, and it may partly explain the distribution trends of $\mathrm{HCHs}$ and DDTs in the shallow groundwater in the study area. According to the static water table of 52 monitoring wells and drinking wells, the hydraulic gradient in the study area was very small and the velocity of horizontal flow was very low. The low velocity of horizontal flow maybe could explain the phenomenon that HCHs and DDTs concentrations in some wells had significant differences even they are very close.

\subsection{Composition and sources}

Previous studies have shown that OCPs in current environmental media are mixtures of historical residues and fresh inputs from current illegal use and impurities in other pesticides [12, 36, 37]. To eliminate the fresh inputs of OCPs, it is necessary to identify the sources of OCPs in the environment. Differences in composition of OCP isomers/metabolites in the environment can reveal different pollution sources $[38,39]$ and various ratios have been used to identify the sources of OCPs [40-43]. However, the OCPs in groundwater are not derived from direct inputs and the ratios of OCP isomers/metabolites will change during transport due to differences in their physical and chemical properties. Some ratios may be inadequate for the evaluation of old and new sources of OCPs in groundwater despite their widespread use to identify old and new OCP sources in other environment media such as soils, sediments and surface waters.

Generally, technical HCH consists of $60-70 \% \alpha-\mathrm{HCH}, 5-12 \% \beta-\mathrm{HCH}$, $10-15 \% \gamma-\mathrm{HCH}$, and $6-10 \% \delta-\mathrm{HCH}$, and the $\alpha-\mathrm{HCH} / \gamma-\mathrm{HCH}$ ratio is in the range of 4-7 [44-46]. In contrast, lindane consists almost entirely of $\gamma-\mathrm{HCH}$. The average percentages of $\mathrm{HCH}$ isomers in the shallow groundwater of Shengzhou were $\alpha-\mathrm{HCH}: 13.2 \%, \beta-\mathrm{HCH}: 19.4 \%, \gamma-\mathrm{HCH}$ : 


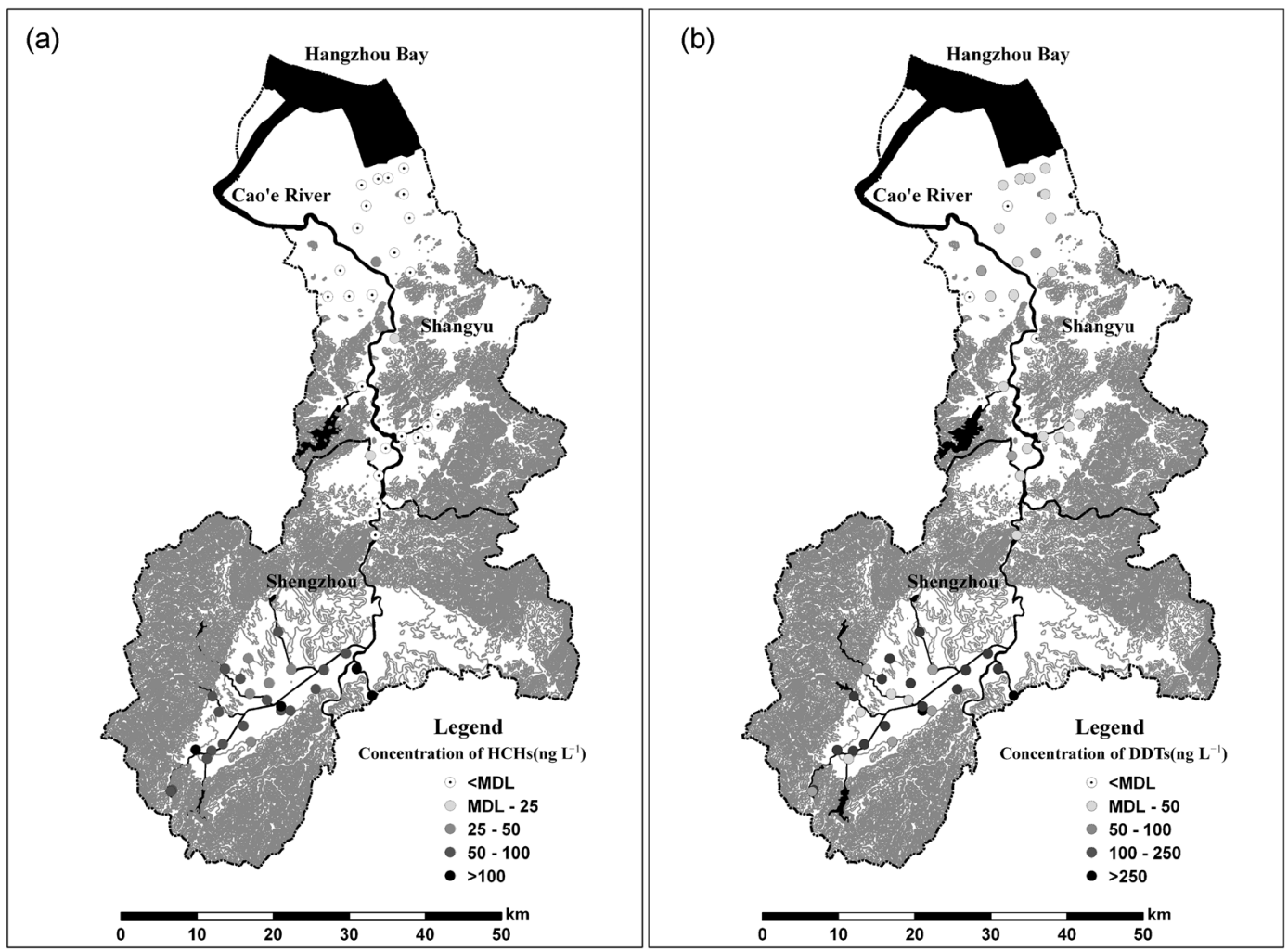

Figure 2. The concentration levels of $\mathrm{HCHs}$ and DDTs in shallow groundwater of study area.

$22.3 \%$, and $\delta-\mathrm{HCH}: 45.1 \%$, and the $\alpha-\mathrm{HCH} / \gamma-\mathrm{HCH}$ ratio was in the range of $0.20-1.37$ with a mean of 0.62 (Tab. 4).

The low $\alpha-\mathrm{HCH} / \gamma-\mathrm{HCH}$ ratio in the shallow groundwater of Shengzhou indicated that there may be some fresh input sources of $\mathrm{HCH}$ in addition to the historical residues. The agricultural application of lindane may have been one of the main fresh input sources of $\mathrm{HCH}$ in the shallow groundwater of the Shengzhou. Since earlier study has shown that the surface waters of Qiantang River, the watershed of which covers Shengzhou and Shangyu, may have new input of lindane and dicofol [47]. The concern of fresh input sources of $\mathrm{HCH}$ in the shallow groundwater of Shengzhou should be raised. Previous studies showed that the water solubilities of $\gamma-\mathrm{HCH}$ and $\delta-\mathrm{HCH}$ are higher than that of $\alpha-\mathrm{HCH}$ and $\beta-\mathrm{HCH}$, and $\gamma-\mathrm{HCH}$ is more volatile than $\delta$ - $\mathrm{HCH}$ for $\gamma-\mathrm{HCH}$ had a higher vapor pressure than $\delta$-HCH [48]. It maybe could partly explain the predominance of $\delta$ - $\mathrm{HCH}$ among the $\mathrm{HCH}$ isomers in the shallow groundwater of Shengzhou.

Technical DDT generally contains $80-85 \% p, p^{\prime}$-DDT and $15-20 \%$ $o, p^{\prime}$-DDT $[49,50]$. In contrast, dicofol, a currently widely used pesticide in China, contains on average $1.7 \% p, p^{\prime}$-DDT and $11.4 \% o, p^{\prime}$-DDT that is indicative of DDTs as impurities in dicofol [51, 52]. If there were no new technical DDT input, the compositional percentage of $p, p^{\prime}$-DDT would decrease and the metabolites DDE + DDD would increase. The two DDT metabolites are more stable and more persistent than DDT itself [53]. Therefore, the ratio of $(\mathrm{DDE}+\mathrm{DDD}) / \Sigma \mathrm{DDT}$ and $p, p^{\prime}$-DDT/2DDTs can be used as valid indicators to identify a recent input of technical DDT [42, 43, 54]. The average percentage of DDT isomers/metabolites in the shallow groundwater of Shengzhou were $p, p^{\prime}$-DDE: $14.9 \%, p, p^{\prime}$-DDD: $10.5 \%$, $o, p^{\prime}$-DDT: $55.0 \%$, and $p, p^{\prime}$-DDT: $19.6 \%$, and $o, p^{\prime}$-DDT dominated the DDT metabolites in the shallow groundwater of Shengzhou. This indicates that there may be some fresh input sources of DDT in addition to the historical residues, and agricultural application of dicofol may have been one of main fresh input sources of DDT in the shallow groundwater of Shengzhou. In the present study, the ratio of (DDE + DDD)/¿DDTs varied from 0.06 to 1.00 (mean 0.28) in the shallow groundwater of Shengzhou and the ratios of $(\mathrm{DDE}+\mathrm{DDD}) / \Sigma \mathrm{DDT}$ for the majority of groundwater samples collected from Shengzhou were $<0.5$, indicating that there was a recent input of DDT in Shengzhou. The $p, p^{\prime}$-DDT/ $\Sigma$ DDTs ratio was in

Table 4. Statistics for the ratios of $\mathrm{HCH}$ and DDT isomers/metabolites in the shallow groundwater of the two regions

\begin{tabular}{|c|c|c|c|c|c|}
\hline City & Isomer/metabolite & Min & Mean & Median & Max \\
\hline \multirow[t]{3}{*}{ Shengzhou } & $\alpha-\mathrm{HCH} / \gamma-\mathrm{HCH}(n=26)$ & 0.20 & 0.62 & 0.56 & 1.37 \\
\hline & $(\mathrm{DDD}+\mathrm{DDE}) / \sum \mathrm{DDTs}(n=26)$ & 0.06 & 0.28 & 0.25 & 1.00 \\
\hline & $p, p^{\prime}$-DDT/ $/ \sum \mathrm{DDTs}(n=27)$ & 0.09 & 0.30 & 0.19 & 1.00 \\
\hline Shangyu & $p, p^{\prime}-\mathrm{DDT} / \sum \mathrm{DDTs}(n=12)$ & 0.49 & 0.81 & 0.86 & 1.00 \\
\hline
\end{tabular}

$n$, pair of valid data; $\sum$ DDTs, sum of $p, p^{\prime}-\mathrm{DDD}+p, p^{\prime}-\mathrm{DDE}+o, p^{\prime}-\mathrm{DDT}+p, p^{\prime}$-DDT; Min, minimum; Max, maximum. 


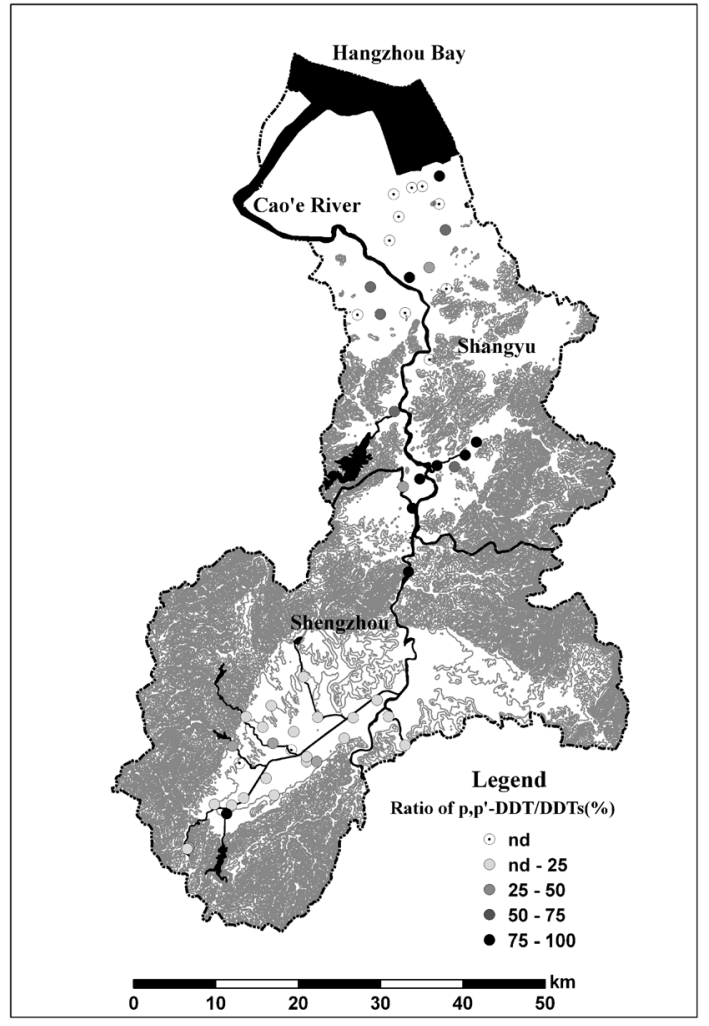

Figure 3. The ratio of $p, p^{\prime}-\mathrm{DDT}$ to DDTs in shallow groundwater of study area.

the range of $0.09-1.00$ with a mean of 0.30 , and the $p, p^{\prime}$-DDT/ $/ 2 D D T s$ ratio for the majority of groundwater samples collected from Shengzhou was $<0.5$ (Fig. 3), indicating that historical residues were also major sources of DDT in the shallow groundwater in Shengzhou.

The average percentages of DDT isomers/metabolites in the shallow groundwater of Shangyu were $p, p^{\prime}$-DDE: $7.86 \%, p, p^{\prime}$-DDD: $0 \%, o, p^{\prime}$-DDT: $35.5 \%$, and $p, p^{\prime}$-DDT: $56.6 \%$, and $p, p^{\prime}$-DDT dominated the DDT metabolites in the shallow groundwater of Shangyu. In the present study, the ratio of $p, p^{\prime}$-DDT/ 2 DDTs was in the range of $0.49-1.00$ with a mean of 0.81 , and the ratios of $p, p^{\prime}$-DDT/ $/ 2 D D T s$ for half of the groundwater samples $(n=11)$ that were collected from Shangyu exceeded 0.5 (Fig. 3), indicating fresh technical DDT usage exist in partial area of Shangyu. A previous study also indicated that fresh technical DDT usage existed in Pearl River Delta, South China [55].

\subsection{Health risk assessment of $\mathrm{HCHs}$ and DDTs in shallow groundwater}

Health risks from drinking local shallow groundwater for adults and children were calculated according to the assessment model. Due to the concentrations of $\mathrm{HCH}$ isomers and DDT isomers/metabolites in the shallow groundwater of the two regions had a wide range, the health risk levels caused by the two OCPs groups for adults and children in the two regions through drinking local shallow groundwater also had wide range. Summary statistics for the health risks caused by the two OCPs groups for adults and children is presented in Tab. 5. For adults, the average cancer risk from drinking local shallow groundwater of Shengzhou was $1.54 \times 10^{-6}$ for $\alpha-\mathrm{HCH}$, $6.48 \times 10^{-7}$ for $\beta$-HCH, $5.39 \times 10^{-7}$ for $\gamma-\mathrm{HCH}, 1.90 \times 10^{-7}$ for $p, p^{\prime}$ DDE, $9.40 \times 10^{-8}$ for $p, p^{\prime}$-DDD and $2.50 \times 10^{-7}$ for $p, p^{\prime}$-DDT, and the average cancer risk from drinking local shallow groundwater of Shangyu was $1.43 \times 10^{-8}$ for $p, p^{\prime}$-DDE, and $1.03 \times 10^{-7}$ for $p, p^{\prime}$-DDT. While for children, the average cancer risk from drinking local shallow groundwater of Shengzhou was $3.31 \times 10^{-6}$ for $\alpha-\mathrm{HCH}$, $1.39 \times 10^{-6}$ for $\beta-\mathrm{HCH}, 1.16 \times 10^{-6}$ for $\gamma-\mathrm{HCH}, 4.08 \times 10^{-7}$ for $p, p^{\prime}$-DDE, $2.01 \times 10^{-7}$ for $p, p^{\prime}$-DDD and $5.35 \times 10^{-7}$ for $p, p^{\prime}$-DDT, and the average cancer risk from drinking local shallow groundwater of Shangyu was $3.07 \times 10^{-8}$ for $p, p^{\prime}$-DDE, and $2.21 \times 10^{-7}$ for $p, p^{\prime}$-DDT.

For the majority of the shallow groundwater samples of Shengzhou, the cancer risk caused by $\alpha-\mathrm{HCH}, \beta-\mathrm{HCH}, \gamma-\mathrm{HCH}$ for children and $\alpha-\mathrm{HCH}$ for adults through drinking was greater than the acceptable risk level $\left(1 \times 10^{-6}\right)$ recommended by US EPA for carcinogens, respectively. It indicated that the current levels of $\mathrm{HCH}$ isomer in the shallow groundwater in majority area of Shengzhou posed serious cancer risk to the local population, especially to children, and the shallow groundwater in majority area of Shengzhou was not suitable for drinking water. Cancer risk from each pollutant in the shallow groundwater of Shengzhou was in the order of $\alpha-\mathrm{HCH}>\beta-\mathrm{HCH}>\gamma-\mathrm{HCH}>p, p^{\prime}-\mathrm{DDT}>p, p^{\prime}-\mathrm{DDE}>p, p^{\prime}-$ $\mathrm{DDD}$, the predominance of $\alpha-\mathrm{HCH}$ suggested that the three $\mathrm{HCH}$ isomers were the main cancer risk factor in the shallow groundwater of Shengzhou. Although the average cancer risk caused by $p, p^{\prime}$-DDT for children through drinking local shallow groundwater of Shengzhou was lower than the acceptable risk level, there were

Table 5. Summary statistics for the health risks caused by $\mathrm{HCH}$ isomers and DDT isomers/metabolites for adults and children (in parentheses) in the two regions through drinking shallow groundwater

\begin{tabular}{|c|c|c|c|c|c|}
\hline \multirow[b]{2}{*}{ City } & \multirow[b]{2}{*}{ Isomer/metabolite } & \multicolumn{2}{|c|}{ Cancer risk $\left(10^{-6}\right)$} & \multicolumn{2}{|c|}{ Hazard quotient $\left(10^{-2}\right)$} \\
\hline & & Range & Mean & Range & Mean \\
\hline \multirow[t]{6}{*}{ Shengzhou $(n=30)$} & $\alpha-\mathrm{HCH}$ & $0-3.72(0-7.97)$ & $1.54(3.31)$ & $0-0.12(0-0.25)$ & $0.05(0.11)$ \\
\hline & $\beta-\mathrm{HCH}$ & $0-3.52(0-7.54)$ & $0.65(1.39)$ & $0-0.98(0-2.09)$ & $0.18(0.39)$ \\
\hline & $\gamma-\mathrm{HCH}$ & $0-1.43(0-3.06)$ & $0.54(1.16)$ & $0-0.37(0-0.78)$ & $0.14(0.30)$ \\
\hline & $p, p^{\prime}-\mathrm{DDE}$ & $0-0.44(0-0.94)$ & $0.19(0.41)$ & - & - \\
\hline & $p, p^{\prime}$-DDD & $0-0.29(0-0.63)$ & $0.09(0.20)$ & $0-0.06(0-0.13)$ & $0.02(0.04)$ \\
\hline & $p, p^{\prime}$-DDT & $0-0.52(0-1.12)$ & $0.25(0.54)$ & $0-0.31(0-0.66)$ & $0.15(0.31)$ \\
\hline \multirow[t]{2}{*}{ Shangyu $(n=22)$} & $p, p^{\prime}-\mathrm{DDE}$ & $0-0.14(0-0.30)$ & $0.01(0.03)$ & - & - \\
\hline & $p, p^{\prime}$-DDT & $0-0.42(0-0.90)$ & $0.10(0.22)$ & $0-0.25(0-0.53)$ & $0.06(0.13)$ \\
\hline
\end{tabular}

-, no given reference dose of the contaminant via oral exposure route parameter value. 
two groundwater samples that posed serious cancer risk $\left(>1 \times 10^{-6}\right)$ to children. To all shallow groundwater samples of Shangyu, cancer risk from each pollutant in the shallow groundwater was lower than the acceptable risk level $\left(1 \times 10^{-6}\right)$ recommended by US EPA for carcinogens, indicating the carcinogenic risk to human health from drinking local groundwater was acceptable.

The HQs of HCH isomers and DDT isomers/metabolites through drinking shallow groundwater for individuals was also calculated according to the assessment model. According to the standards [35], when the ratio exceeds 1 , it means that it has an adverse human health effect. In our work, non-carcinogenic risks from $\mathrm{HCHs}$ and DDTs for adults and children were further $<1$, suggesting that $\mathrm{HCHs}$ and DDTs in the shallow groundwater of the study area were considered unlikely to pose any adverse health effects to individuals. Due to lack of relevant parameters (slope factor and reference dose) for $\delta$-HCH and $o, p^{\prime}$-DDT, both cancer risks and HQs caused by them were not calculated. However, $\delta$-HCH and $o, p^{\prime}$-DDT in some shallow groundwater samples had high concentration, and the heath risks caused by them through drinking should not be neglected.

Research and study on OCPs pollution in water has been well documented around the world. However, there have been few reports on health risks caused by OCPs through drinking water, especially drinking groundwater. Comparing with underground rivers in Chongqing [31], surface water in Hanzhou [56], Jiulong River Estuary in China [57], both the total carcinogenic risk of $\mathrm{HCH}$ isomers and the total carcinogenic risk of DDT isomers/metabolites in Shengzhou were obvious higher, while the total carcinogenic risk of DDT isomers/metabolites in Shangyu was very close.

\section{Concluding remarks}

$\mathrm{HCH}$ and DDT residues are detected in the shallow groundwater of most Shengzhou and parts of Shangyu area with large spatial variation in the concentration. There are significant differences in the composition of $\mathrm{HCH}$ isomers and DDT isomers/metabolites in the shallow groundwater between the two regions. $\delta$ - $\mathrm{HCH}$ was the dominant $\mathrm{HCH}$ isomers in the shallow groundwater of Shengzhou, and $o, p^{\prime}$-DDT and $p, p^{\prime}$-DDT were the dominant DDT isomers/ metabolites in the shallow groundwater of Shengzhou and Shangyu, respectively. The possible sources of HCHs and DDTs in the shallow groundwater of Shengzhou and Shangyu were identified by their composition of isomers/metabolites. The low $\alpha-\mathrm{HCH} / \gamma-\mathrm{HCH}$ ratio, low $(\mathrm{DDE}+\mathrm{DDD}) / \Sigma \mathrm{DDT}$ ratio and $o, p^{\prime}$-DDT being the dominant DDT metabolite for the majority of groundwater samples collected from Shengzhou indicated that there probably existed fresh lindane and dicofol usage in majority area of Shengzhou. The

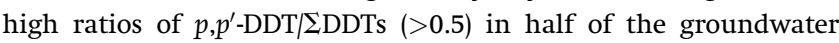
samples of Shangyu indicated there probably existed fresh technical DDT usage in parts of Shangyu.

The health risks from drinking local shallow groundwater for adults and children were estimated. The results show the three $\mathrm{HCH}$ isomers $(\alpha-\mathrm{HCH}, \beta-\mathrm{HCH}$, and $\gamma-\mathrm{HCH})$ in the shallow groundwater in majority area of Shengzhou pose a serious cancer risk to children, and $\alpha-\mathrm{HCH}$ is the priority pollutant for cancer risks. This suggests that the three $\mathrm{HCH}$ isomers in the shallow groundwater of Shengzhou should be controlled urgently and effectively. There were two groundwater samples with high concentration of $p, p^{\prime}$-DDT posing serious cancer risk $\left(>1 \times 10^{-6}\right)$ to children, and the cancer risk caused by $p, p^{\prime}$-DDT in parts of Shengzhou should also be controlled. Although the cancer risks caused by all the DDT isomers/metabolites through drinking local shallow groundwater in majority area of Shengzhou and whole Shangyu were lower than the acceptable risk level, considerable attention should be paid to the new input of DDTs.

\section{Acknowledgments}

This research was funded in part by the Environmental Protection Commonwealth Industry Research Special Project (Grant No. 201109017-1), Chinese Academy of Sciences knowledge Innovation Program (Grant No: KZCX2-YW-BR-19), and the National Natural Science Foundation of China (Grant No. 41001315). We appreciate all the colleagues who collected and analyzed the soil samples. We also extend great appreciation to two anonymous reviewers and Dr. Ayrton Martins of the Rural Federal University of Rio de Janeiro, for their comments. The authors are very grateful to Dr. Peter J. Christie of Queen's University Belfast for his contributions to this manuscript.

The authors have declared no conflict of interest.

\section{References}

[1] J. Beard, S. Marshall, K. Jong, R. Newton, T. Triplett-McBride, B. Humphries, R. Bronks, 1,1,1-Trichloro-2,2-bis(p-chlorophenyl)ethane (DDT) and Reduced Bone Mineral Density, Arch. Environ. Health 2000, 55 (3), 177-180.

[2] T. Colborn, F. S. vom Saal, A. M. Soto, Developmental Effects of Endocrine-Disrupting Chemicals in Wildlife and Humans, Environ. Health Perspect. 1993, 101 (5), 378-384.

[3] W. R. Kelce, C. R. Lambright, L. E. Gray, K. P. Roberts, Vinclozolin and $p, p$-DDE Alter Androgen-Dependent Gene Expression: In Vivo Confirmation of an Androgen Receptor-Mediated Mechanism, Toxicol. Appl. Pharmacol. 1997, 142, 192-200.

[4] M. T. Ahmed, N. Loutfy, E. El. Shieke, Residue Levels of DDE and PCBs in Blood Serum of Women in Port Said in Egypt, J. Hazard Mater. 2002, $89,41-48$.

[5] K. A. McGlynn, C. C. Abnet, M. Zhang, X. D. Sun, J. H. Fan, T. R. O'Brien, W. Q. Wei, et al., Serum Concentrations of 1,1,1Trichloro-2,2-bis(p-chlorophenyl)ethane (DDT) and 1,1-Dichloro-2,2bis(p-chlorophenyl)ethylene (DDE) and Risk of Primary Liver Cancer, J. Nat. Cancer Inst. 2006, 98, 1005-1010.

[6] M. S. Wolff, P. G. Toniolo, E. W. Lee, M. Rivera, N. Dubin, Blood Levels of Organochlorine Residues and Risk of Breast Cancer, J. Nat. Cancer Inst. 1993, 85 (8), 648-652.

[7] S. Ennaceur, D. Ridha, R. Marcos, Genotoxicity of the Organochlorine Pesticides 1,1-Dichloro-2,2-3-bis(p-chlorophenyl) Ethylene (DDE) and Hexachlorobenzene (HCB) in Cultured Human Lymphocytes, Chemosphere, 2008, 71 (7), 1335-1339.

[8] S. Ennaceur, N. Gandoura, M. R. Driss, Distribution of Polychlorinated Biphenyls and Organochlorine Pesticides in Human Breast Milk from Various Locations in Tunisia: Levels of Contamination, Influencing Factors, and Infant Risk Assessment, Environ. Res. 2008, 108, 86-93.

[9] D. B. Wei, T. Kameya, K. Urano, Environmental Management of Pesticidal POPs in China: Past, Present and Future, Environ. Int. 2007, 33, 894-902.

[10] Y. F. Li, D. J. Cai, A. Singh, Technical Hexachlorocyclohexane Use Trends in China and Their Impact on the Environment, Arch. Environ. Contam. Toxicol. 1998, 35, 688-697.

[11] Y. F. Li, D. J. Cai, A. Singh, Historical DDT Use Trend in China and Usage Data Gridding with $1 / 4$ by $1 / 6$ Longitude/Latitude Resolution, Adv. Environ. Res. 1999, 2, 497-506.

[12] J. Li, G. Zhang, S. Qi, X. Li, X. Peng, Concentrations, Enantiomeric Compositions, and Sources of HCH, DDT and Chlordane in Soils from the Pearl River Delta, South China, Sci. Total Environ. 2006, 372, 215-224. 
[13] X. L. Yang, S. S. Wang, Y. R. Bian, F. Chen, G. F. Yu, C. G. Gu, X. Jiang, Dicofol Application Resulted in High DDTs Residue in Cotton Fields from Northern Jiangsu Province, China, J. Hazard. Mater. 2008, 150 (1), 92-98.

[14] J.H. Kim, A. Smith, Distribution of Organochlorine Pesticides in Soils from South Korea, Chemosphere 2001, 43, 137-140.

[15] H. B. Zhang, Y. M. Luo, Q. B. Li, Burden and Depth Distribution of Organochlorine Pesticides in the Soil Profiles of Yangtze River Delta Region, China: Implication for Sources and Vertical Transportation, Geoderma 2009, 153, 69-75.

[16] Z. Ayas, N. Barlas, Determination of Organochlorine Pesticide Residues in Various Environments and Organisms in Göksu Delta, Turkey, Aquat. Toxicol. 1997, 39, 171-181.

[17] E. D. Caldas, R. Coelho, L. C. Souza, S. C. Silva, Organochlorine Pesticides in Water, Sediment and Fish of Pavanoa Lake of Brasilia, Brazil, Bull. Environ. Contam. Toxicol. 1999, 62, 199-206.

[18] W. Tieyu, L. Yonglong, Z. Hong, S. Yajuan, Contamination of Persistent Organic Pollutants (POPs) and Relevant Management in China, Environ. Int. 2005, 31, 813-821.

[19] L. L. Shi, Z. J. Shan, D. Y. Kong, D. J. Cai, The Health and Ecological Impacts of Organochlorine Pesticide Pollution in China: Bioaccumulation of Organochlorine Pesticides in Human and Fish Fats, Hum. Ecol. Risk Assess. 2006, 12, 402-407.

[20] H. Nakata, M. Kawazoe, K. Arizono, S. Abe, T. Kitano, H. Shimada, W. Li, X. Ding, Organochlorine Pesticides and Polychlorinated Biphenyl Residues in Foodstuffs and Human Tissues from China: Status of Contamination, Historical Trend and Human Dietary Exposure, Arch. Environ. Contam. Toxicol. 2002, 43, 473-480.

[21] F. Meng, J. Zhang, M. Liu, Y. X. Wu, Distribution of HCHs and DDTs in Agricultural Soil of Shanghai (in Chinese with English Abstract), Acta Pedologica Sin. 2009, 46 (2), 361-364.

[22] Z. M. Gong, F. L. Xu, R. Dawson, J. Cao, W. X. Liu, B. G. Li, W. R. Shen, et al., Residues of Hexachlorocyclohexane Isomers and Their Distribution Characteristics in Soils in the Tianjin Area, China, Arch. Environ. Contam. Toxicol. 2004, 46, 432-437.

[23] F. M. Jaward, G. Zhang, J. J. Nam, A. J. Sweetman, J. P. Obbard, Y. Kobara, K. C. Jones, Passive Air Sampling of Polychlorinated Biphenyls, Organochlorine Compounds, and Polybrominated Diphenyl Ethers across Asia, Environ. Sci. Technol. 2005, 39, 8638-8645.

[24] X. Liu, G. Zhang, J. Li, L. L. Yu, Y. Xu, X. D. Li, Y. Kobara, K. C. Jones, Seasonal Patterns and Current Sources of DDTs, Chlordanes, Hexachlorobenzene, and Endosulfan in the Atmosphere of 37 Chinese Cities, Environ. Sci. Technol. 2009, 43, 1316-1321.

[25] Y. Wu, J. Zhang, Q. Zhou, Persistent Organochlorine Residues in Sediments from Chinese River/Estuary Systems, Environ. Pollut. 1999, 105, 143-150.

[26] H. B. Zhang, Y. M. Luo, Q. G. Zhao, M. H. Wong, G. L. Zhang, Residues of Organochlorine Pesticides in Hong Kong Soils, Chemosphere 2006, 63, 633-641.

[27] Y. H. Wang, S. J. Guo, R. Xue, S. H. Qi, Y. Y. Xu, B. M. Xue, D. X. Yuan, Organochlorine Pesticides in the Soil of a Karst Cave in Guilin, China, Environ. Monit. Assess. 2011, 180 (1-4), 489-500.

[28] Q. B. Li, H. B. Zhang, Y. M. Luo, J. Song, L. H. Wu, J. M. Ma, Residues of DDTs and Their Spatial Distribution Characteristics in Soils from the Yangtze River Delta, China, Environ. Toxicol. Chem. 2008, 27, 24-30.

[29] Hydrogeological and Engineering Geological Brigade of Zhejiang Province, Zhejiang Province Hydrology and Geology, Geology Press, Beijing 1995.

[30] K. Phan, S. Sthiannopkao, K. W. Kim, M. H. Wong, V. Sao, J. H. Hashim, M. S. Mohamed Yasin, S. M. Aljunid, Health Risk Assessment of Inorganic Arsenic Intake of Cambodia Residents through Groundwater Drinking Pathway, Water Res. 2010, 44, 57775788.

[31] Y. Hu, S. H. Qi, J. P. Zhang, L. Z. Tan, J. Q. Zhang, Y. H. Wang, D. X. Yuan, Assessment of Organochlorine Pesticides Contamination in Underground Rivers in Chongqing, Southwest China, J. Geochem. Explor. 2011, 111, 47-55.
[32] US EPA, IRIS (Integrated Risk Information System), US Environmental Protection Agency, Cincinnati, OH 2005.

[33] US EPA (US Environmental Protection Agency), Risk Assessment Guidance for Superfund, Human Health Evaluation Manual (Part A), Vol. I, EPA/540/1-89/002, Office of Emergency and Remedial Response, Washington, DC 1989, p. 198.

[34] US EPA (US Environmental Protection Agency), Exposure Factors Handbook, EPA/600/P-95/002Fa, Office of Research and Development National Center for Environmental Assessment, Washington, DC 1997.

[35] US EPA (US Environmental Protection Agency), Guidelines for the Health Risk Assessment of Chemical Mixtures, Office of Emergency and Remedial Response, Washington, DC 1986.

[36] K. P. Singh, A. Malik, D. Mohan, Persistent Organochlorine Pesticide Residues in Alluvial Groundwater Aquifers of Gangetic Plains, India, Bull. Environ. Contam. Toxicol. 2005, 74 (1), 162-169.

[37] J. Li, G. Zhang, L. L. Guo, W. H. Xu, X. D. Li, A. J. Ding, T. Wang, Organochlorine Pesticides in the Atmosphere of Guangzhou and Hong Kong: Regional Sources and Long-Range Atmospheric Transport, Atmos. Environ. 2007, 41, 3889-3903.

[38] R. A. Doong, C. K. Peng, Y. C. Sun, P. L. Liao, Composition and Distribution of Organochlorine Pesticide Residues in Surface Sediments from the Wu-Shi River Estuary, Taiwan, Mar. Pollut. Bull. 2002, 45, 246-253.

[39] R. B. Zhou, L. Z. Zhu, K. Yang, Y. Y. Chen, Distribution of Organochlorine Pesticides in Surface Water and Sediments from Qiantang River, East China, J. Hazard. Mater. 2006, 137, 68-75.

[40] B. Strandberg, B. van Bavel, P. A. Bergvist, D. Bronman, R. Ishaq, C. Näf, H. Pettersen, et al., Occurrence, Sedimentation, and Spatial Variations of Organochlorine Contaminants in Settling Partculate Matter and Sediments in the Northern Part of the Baltic Sea, Environ. Sci. Technol. 1998, 32, 1754-1759.

[41] T. F. Bidleman, Atmospheric Transport and Air-Surface Exchange of Pesticides, Water Air Soil Pollut. 1999, 115, 115-166.

[42] H. Hong, W. Chen, L. Xu, X. Wang, L. Zhang, Distribution and Fate of Organochlorine Pollutants in the Pearl River Estuary, Mar. Pollut. Bull. 1999, 39, 376-382.

[43] A. C. Covaci, P. S. Hurab, Selected Persistent Organochlorine Pollutants in Romania, Sci. Total Environ. 2001, 280, 143-152.

[44] H. Iwata, N. Tanabe, N. Sakai, R. Tatsukawa, Distribution of Persistent Organochlorines in the Oceanic Air and Surface Seawater and the Role of Ocean on Their Global Transport and Fate, Environ. Sci. Technol. 1993, 27, 1080-1098.

[45] H. R. Buser, M. D. Müller, Isomer and Enantioselective Degradation of Hexachlorocyclohexane Isomers in Sewage Sludge under Anaerobic Conditions, Environ. Sci. Technol. 1995, 29, 664-672.

[46] Y. F. Li, R. W. Macdonald, Sources and Pathways of Selected Organochlorine Pesticides to the Arctic and the Effect of Pathway Divergence on HCH Trends in Biota: A Review, Sci. Total Environ. 2005, 342, 87-106.

[47] R. B. Zhou, L. Z. Zhu, Y. Y. Chen, Levels and Source of Organochlorine Pesticides in Surface Waters of Qiantang River, China, Assess. Environ. Monit. 2008, 136, 277-287.

[48] ATSDR (Agency for Toxic Substances and Disease Registry), Toxicological Profile for alpha-, beta-, gamma, and delta-Hexachlorocyclohexane, ATSDR, Atlanta, GA 2005, p. 176.

[49] R. L. Metcalf, A Century of DDT, J. Agric. Food Chem. 1973, 21, 511-520.

[50] R. F. Bopp, H. J. Simpson, R. M. Trier, N. Kostyk, Chlorinated Hydrocarbons and Radionuclide Chronologies in Sediments of the Hudson River and Estuary, New York, Environ. Sci. Technol. 1982, 16, 666-676.

[51] X. H. Qiu, T. Zhu, B. Yao, J. X. Hu, S. W. Hu, Contribution of Dicofol to the Current DDT Pollution in China, Environ. Sci. Technol. 2005, 39, 4385-4390.

[52] X. H. Qiu, T. Zhu, L. Jing, H. S. Pan, Q. L. Li, G. F. Miao, J. C. Gong, Organochlorine Pesticides in the Air around the Taihu Lake, China, Environ. Sci. Technol. 2004, 38, 1368-1374. 
[53] R. Bossi, B. Laesen, G. Premazze, Polychlorinated Biphenyl Congeners and Other Chlorinated Hydrocarbons in Bottom Sediment Cores of Lake Garda (Italy), Sci. Total Environ. 1992, 121 77-93.

[54] K. T. Lee, S. Tanabe, C. H. Koh, Distribution of Organochlorine Pesticides in Sediments from Kyeonggi Bay and Nearby Areas, Korea, Environ. Pollut. 2001, 114, 207-213.

[55] J. Li, G. Zhang, S. H. Qi, X. D. Li, X. Z. Peng, Concentrations, Enantiomeric Compositions, and Sources of $\mathrm{HCH}$, DDT and
Chlordane in Soils from the Pearl River Delta, South China, Sci. Total Environ. 2006, 372, 215-224.

[56] Q. Sun, L. Zhu, M. Dong, Risk Assessment of Organic Pesticides Pollution in Surface Water of Hangzhou, Monit. Assess. Environ. 2006 117, 377-385.

[57] Z. L. Zhang, H. S. Hong, X. H. Wang, J. Q. Lin, W. Q. Chen, L. Xu, Determination and Load of Organophosphorus and Organochlorine Pesticides at Water from Jiulong River Estuary, China, Mar. Pollut. Bull. 2002, 45, 397-402. 